\title{
Refatorando um Pipeline de Bioinformática: Um Estudo de Caso para Análise de Amplicons
}

\author{
Aline Mara Rudsit Bini ${ }^{1}$, Liliane Santana Oliveira ${ }^{2}$, \\ Heloisa Poliselo $^{2}$, Francismar Correa Marcelino Guimaraes ${ }^{2}$, \\ André Yoshiaki Kashiwabara ${ }^{1}$ \\ ${ }^{1}$ Departamento de Computação - Universidade Tecnológica Federal \\ do Paraná (UTFPR) - Cornélio Procópio - PR - Brazil \\ ${ }^{2}$ Embrapa Soja - Londrina - PR - Brazil \\ alinebini@alunos.utfpr. edu.br
}

\begin{abstract}
Bioinformatic pipelines are essential to make it possible to process the enormous amount of available biological data. An approach in analyzing biological data is to implement scripts using a programming language such as Perl, Python, R, or Bash. However, these scripts can be hard to maintain and to understand by other developers. In this work, we refactored a pipeline for amplicon analysis from NGS (next-generation sequencig) data implemented in Perl to make it scalable, portable, with simplified code and parallelization of existing processes. For this, we used a workflow manager called Nextflow.
\end{abstract}

Resumo. Os pipelines de bioinformática são essenciais para possibilitar o processamento da enorme quantidade de dados biológicos disponíveis. Uma abordagem na análise de dados biológicos consiste em implementar scripts usando uma linguagem de programação como Perl, Python, $R$ ou Bash. No entanto, esses scripts podem ser dificeis de serem mantidos e compreendidos por outros desenvolvedores. Neste trabalho, reimplementamos um pipeline para análise de amplicons, implementado em Perl, para torná-lo escalável, portável, com código simplificado e para a paralelização de seus processos. Para isso, utilizamos um gerenciador de workflow denominado Nextflow.

\section{Introdução}

Um workflow é uma forma de organizar diferentes tarefas a serem executadas, de forma a gerar um resultado final. É possível criar diferentes estruturas com estas tarefas, sendo uma delas o pipeline, caracterizado por ser uma arquitetura de software amplamente utilizada quando o objetivo da análise consiste no processamento de dados, visto que ele possui vantagens como: facilidade de compreensão do comportamento geral do sistema; suporte a reutilização; capacidade de aprimoramento; análise especializada; e execução paralela de seus componentes [Garlan and Shaw 1993]. Estas características provêm de sua topologia, a qual é baseada em pipes e filtros. Os pipes formam um canal unidirecional de comunicação entre os filtros, o qual recebe uma entrada e a direciona para uma saída após realizar uma tarefa [Richards and Ford 2020].

Com isto, muitos experimentos têm sido compartilhados em forma de pipelines no intuito de disponibilizá-los para a comunidade científica. Entretanto, eles são, 
em sua maioria, projetados para uso local, o que aumenta as chances de ocorrer problemas como irreprodutibilidade computacional, má utilização de software e de banco de dados e variações entre plataformas, que pode resultar em instabilidade numérica e códigos não modulares, com difícil compreensão e adaptação. Estes fatores são prejudiciais principalmente quando trabalhamos com aplicações em ambientes computacionais de alto desempenho (HPC), os quais são frequentemente utilizados em análises ômicas [Di Tommaso et al. 2017].

Para ajudar a resolver alguns desses problemas, existem vários sistemas de gerenciamento de workflows para bioinformática: Galaxy [Goecks et al. 2010], Snakemake [Köster and Rahmann 2012], Bpipe [Sadedin et al. 2012], EGene [Durham et al. 2005] e o Nextflow [Di Tommaso et al. 2017].

O presente trabalho iniciou-se com um projeto da EMBRAPA-Soja relacionado a Seleção Assistida de plantas de soja para a resistência à Ferrugem Asiática através da tecnologia de sequenciamento paired-end de fragmentos amplificados em PCR (amplicons) em diferentes loci. Em sua fase final, foi aplicado um pipeline [Fresnedo-Ramírez et al. 2019] para realizar as análises dos polimorfismos presentes nestes amplicons. Contudo, devido à dificuldade de interpretação do código, programas não utilizados na análise, e de outros fatores que não garantem a reprodutibilidade das análises, foi realizada a reimplementação do código utilizando um gerenciador de workflow, o Nextflow, tornando o pipeline modular, escalonável e portátil, além de arquivos com o resumo de todo o processamento graficamente.

\section{Material e Métodos}

Para a reimplementação do pipeline, foi necessário identificar e entender os passos que foram implementados no script original escrito na linguagem Perl [Fresnedo-Ramírez et al. 2019]. Este realiza o processamento de dados produzidos pelo sequenciamento de short reads de DNA pela tecnologia Illumina, após PCR e multiplexação. Sua entrada é um conjunto de dois arquivos com extensão ".fastq"por amostra, uma pertencente à fita direta e outra à reversa do DNA. Através dele é possível a obtenção de diferentes haplótipos ${ }^{1}$ referentes às regiões desejadas, a fim de explorar polimorfismos existentes.

A Figura 1 descreve os passos do pipeline: (i) é realizado o corte dos adaptadores utilizados durante o sequenciamento, além do descarte de leituras (sequências) com qualidade abaixo do especificado pelo usuário. Para o corte, é utilizado o software Trimmomatic [Bolger et al. 2014]; (ii) há a verificação dos pares das leituras, por tratar-se de sequenciamento paired-end, descartando pares que não possuem sobreposição entre si. Para encontrar as sobreposições, é aplicado o software Flash [Magoč and Salzberg 2011]; (iii) as leituras em cada arquivo são separadas de acordo com as sequências dos primers. Este pré-processamento é feito através de uma das ferramentas do FASTX-Toolkit, o Barcode Splitter [Gordon et al. 2010]; (iv) efetua-se uma divisão de acordo com cada uma das amostras e suas leituras. Também é utilizado o FASTX-Toolkit, porém com a ferramenta Collapser; (v) é realizada uma segunda divisão das leituras, porém agora de acordo com os primers, novamente aplicando o Collapser; (vi) são criadas duas tabelas para

\footnotetext{
das

${ }^{1}$ Grupos de sequências similares que apresentam os mesmos polimorfismos referentes a regiões deseja-
} 
cada região de interesse (especificada por cada primer), uma com as sequências de cada haplótipo encontrado e o total de ocorrências, e outra com quantidade de haplótipos por amostra. Esta etapa é feita inteiramente no script do próprio pipeline; (vii) por fim, são criados arquivos fasta com os haplótipos mais recorrentes, havendo um alinhamento entre eles a fim de especificar as regiões discrepantes. Também são criadas duas tabelas com informações sobre os dois haplótipos mais recorrentes em cada amostra. Para a criação das tabelas, o desenvolvimento é no script do pipeline, e o alinhamento é feito através do software Clustal O [Sievers et al. 2011].

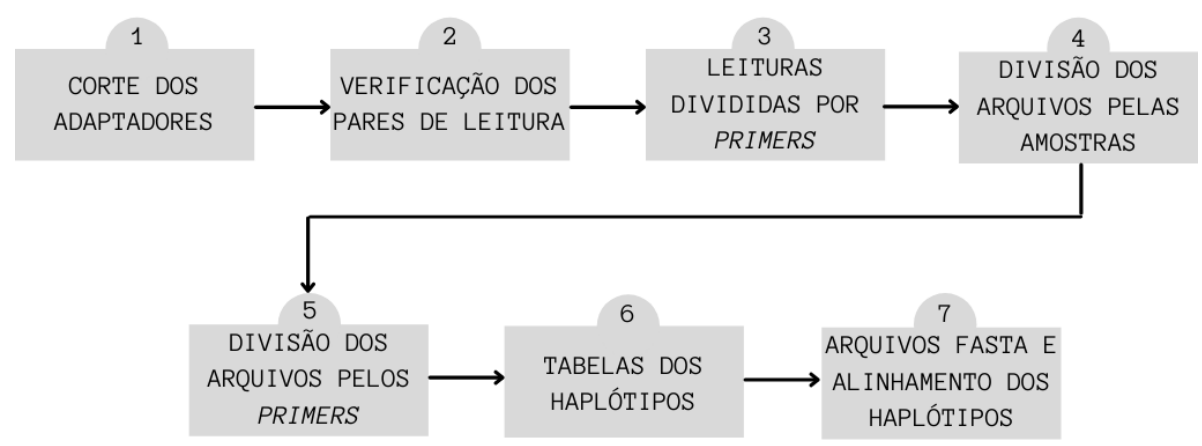

Figura 1. Fluxograma do pipeline

\section{Resultados}

Com a refatoração proposta, a média de linhas de código em cada etapa do pipeline foi reduzida de 139 para 37. Isto porque com o Nextflow a identificação dos arquivos de entrada é substituída pelos canais, e o processamento e utilização das linhas de comando são simplificados na escrita.

Por fim, por meio do Nf-core são gerados gráficos referentes à execução do pipeline e aos resultados. Há gráficos referentes a cada processo quanto a utilização de CPU, porcentagem de memória alocada, tempo de duração, quantidade de número de bytes de leitura e escrita, entre outros. Também, é produzida uma tabela com informações sobre cada execução realizada no workflow em relação a cada arquivo, permitindo a visualização dos comandos executados.

A Tabela 1 mostra o resultado de uma das saídas principais do pipeline. Para cada primer há um conjunto de haplótipos e a frequência em que ocorrem, além da quantidade destes em cada uma das amostras de entrada.

Tabela 1. Resultado de uma das saídas do pipeline refatorado

\begin{tabular}{|c|c|c|}
\hline Primer & Haplótipos & Amostra \\
\hline Ren1_SC47_6 & $1(0.75) ; 2(0.17) ; 4(0.08) ;$ & $2 / 2: 3841$ \\
\hline Ren6_PN9_068 & $3(0.50) ; 1(0.27) ; 2(0.23) ;$ &.$/ .0$ \\
\hline Ren7_PN19_018 & $1(0.67) ; 2(0.33) ;$ & $2 / 2: 152$ \\
\hline Ren7_VVin74 & $2(0.50) ; 1(0.42) ; 3(0.08) ;$ & $2 / 2: 144$ \\
\hline Rpv12_UDV014 & $\begin{array}{c}1(0.38) ; 2(0.25) ; 17(0.17) ; \\
\end{array}$ & $1 / 1: 36$ \\
\hline Rpv12_UDV370 & $1(0.08) ; 21(0.08) ; 3(0.04) ;$ & \\
\hline
\end{tabular}




\section{Conclusão}

O objetivo deste trabalho foi a refatoração de um pipeline voltado para a análise de amplicons provindos de sequenciamento genético. Foi possível organizar o código ao encapsular etapas mais trabalhosas ou com grande número de linhas, tornando-o mais legível e resultando em um código mais simples. Adicionalmente, o arquivo de entrada referente ao nome dos arquivos pôde ser suprimido, e a chamada aos programas não necessita mais ser editada no código-fonte. Além disto, os processos agora são executados paralelamente quando possível, devido à paralelização que o Nextflow provê automaticamente. Por fim, foi possível obter gráficos e tabelas referentes às etapa de execução. $\mathrm{O}$ trabalho encontrase no GitHub do projeto (https://github.com/aalinebini/ampliconseq).

\section{Referências}

Bolger, A. M., Lohse, M., and Usadel, B. (2014). Trimmomatic: a flexible trimmer for illumina sequence data. Bioinformatics, 30(15):2114-2120.

Di Tommaso, P., Chatzou, M., Floden, E. W., Barja, P. P., Palumbo, E., and Notredame, C. (2017). Nextflow enables reproducible computational workflows. Nature biotechnology, 35(4):316-319.

Durham, A. M., Kashiwabara, A. Y., Matsunaga, F. T., Ahagon, P. H., Rainone, F., Varuzza, L., and Gruber, A. (2005). Egene: a configurable pipeline generation system for automated sequence analysis. Bioinformatics, 21(12):2812-2813.

Fresnedo-Ramírez, J., Yang, S., Sun, Q., Karn, A., Reisch, B. I., and Cadle-Davidson, L. (2019). Computational analysis of ampseq data for targeted, high-throughput genotyping of amplicons. Frontiers in plant science, 10:599.

Garlan, D. and Shaw, M. (1993). An introduction to software architecture. In Advances in software engineering and knowledge engineering, pages 1-39. World Scientific.

Goecks, J., Nekrutenko, A., and Taylor, J. (2010). Galaxy: a comprehensive approach for supporting accessible, reproducible, and transparent computational research in the life sciences. Genome biology, 11(8):1-13.

Gordon, A., Hannon, G., et al. (2010). Fastx-toolkit. FASTQ/A short-reads preprocessing tools (unpublished) http://hannonlab. cshl. edu/fastx_toolkit, 5.

Köster, J. and Rahmann, S. (2012). Snakemake-a scalable bioinformatics workflow engine. Bioinformatics, 28(19):2520-2522.

Magoč, T. and Salzberg, S. L. (2011). Flash: fast length adjustment of short reads to improve genome assemblies. Bioinformatics, 27(21):2957-2963.

Richards, M. and Ford, N. (2020). Fundamentals of Software Architecture: An Engineering Approach. O'Reilly Media, Inc.

Sadedin, S. P., Pope, B., and Oshlack, A. (2012). Bpipe: a tool for running and managing bioinformatics pipelines. Bioinformatics, 28(11):1525-1526.

Sievers, F., Wilm, A., Dineen, D., Gibson, T. J., Karplus, K., Li, W., Lopez, R., McWilliam, H., Remmert, M., Söding, J., et al. (2011). Fast, scalable generation of highquality protein multiple sequence alignments using clustal omega. Molecular systems biology, 7(1):539. 